\title{
An inter-comparison of sediment classification methods based on multi-beam echo-sounder backscatter and sediment natural radioactivity data
}

\author{
Mirjam Snellen ${ }^{\text {a) }}$ and Dimitrios Eleftherakis \\ Chair acoustics, Faculty of Aerospace Engineering, Delft University of Technology, Kluyverweg 1, 2629 HS \\ Delft, The Netherlands \\ AliReza Amiri-Simkooeib) \\ Department of Surveying Engineering, Faculty of Engineering, University of Isfahan, Isfahan 81746-73441, \\ Iran \\ Ronald L. Koomans \\ Medusa Explorations BV, Verl. Bremenweg 4, 9723 JV Groningen, P.O. Box 623, 9700 AP Groningen, The \\ Netherlands \\ Dick G. Simons \\ Chair Acoustics, Faculty of Aerospace Engineering, Delft University of Technology, Kluyverweg 1, 2629 HS \\ Delft, The Netherlands
}

(Received 11 May 2012; revised 28 May 2013; accepted 18 June 2013)

\begin{abstract}
This contribution presents sediment classification results derived from different sources of data collected at the Dordtse Kil river, the Netherlands. The first source is a multi-beam echo-sounder (MBES). The second source is measurements taken with a gamma-ray scintillation detector, i.e., the Multi-Element Detection System for Underwater Sediment Activity (Medusa), towed over the sediments and measuring sediment natural radioactivity. Two analysis methods are employed for sediment classification based on the MBES data. The first is a Bayesian estimation method that uses the average backscatter data per beam and, therefore, is independent of the quality of the MBES calibration. The second is a model-based method that matches the measured backscatter curves to theoretical curves, predicted by a physics-based model. Medusa provides estimates for the concentrations of potassium, uranium, thorium, and cesium, known to be indicative for sediment properties, viz. mean grain size, silt content, and the presence of organic matter. In addition, a hydrophone attached to the Medusa system provides information regarding the sediment roughness. This paper presents an inter-comparison between the sediment classification results using the above-mentioned methods. It is shown that although originating from completely different sources, the MBES and Medusa provide similar information, revealing the same sediment distribution.
\end{abstract}

(C) 2013 Acoustical Society of America. [http://dx.doi.org/10.1121/1.4812858]

PACS number(s): 43.30.Pc [NPC]

Pages: 959-970

\section{INTRODUCTION}

Reliable information about the seafloor or riverbed sediment composition is of high interest for a large number of applications such as marine geology, marine biology, offshore construction projects, and cable and pipeline route planning. Traditionally, obtaining information about the sediment distribution in an area requires an extensive set of grab samples of the sediments and subsequent laboratory analysis, which can be costly and time consuming. Alternatively, acoustic remote sensing techniques can be used for classifying the sediments. Since single- and multibeam echo-sounders (SBES, MBES) are already in common

\footnotetext{
a) Author to whom correspondence should be addressed. Electronic mail: m.snellen@tudelft.nl

b) Also at: Chair acoustics, Faculty of Aerospace Engineering, Delft University of Technology, Kluyverweg 1, 2629 HS Delft, The Netherlands.
}

use for depth measurements, an attractive approach is to use the signals measured by these systems also for sediment classification purposes. Sediment classification potential using the MBES and SBES systems has proven to be high. $^{1-7}$

In general, sediment classification methods using SBES and MBES can be divided into phenomenological (or empirical) and model-based (or physical) methods. In the phenomenological methods, features that are indicative for sediment type (e.g., backscatter strength or features derived from the bathymetric measurements) are used for classification. These methods discriminate the sediments as belonging to different acoustic classes, each with its own acoustic features. These acoustic classes represent the different sediment types that are present in the survey area. However, independent information, e.g., from grab samples taken in the area, is usually needed to assign sediment type, such as mud, sand or gravel, or sediment parameters, such as mean grain size, to the acoustic classes. ${ }^{6-9}$ On the contrary, the model-based 
methods ${ }^{10-13}$ determine the sediment type by maximizing the match between modeled and measured signals or signal features, where sediment type, or parameters indicative for sediment type, are input into the model. In principle, no independent information is required for model-based methods, since they provide the sediment type, or properties indicative for sediment type, instead of acoustic classes.

This paper examines two methods for riverbed sediment classification using the MBES. First, a statistical method is applied that utilizes the backscatter strength measurements of an MBES. It uses the backscatter data at a certain angle to obtain the number of sediment classes and to discriminate between them by applying the Bayes decision rule to multiple hypotheses. ${ }^{14,15}$ Although this method can be considered as model-based, employing a model for the backscatter histogram, it classifies the sediments as a number of acoustic classes. Second, a method is employed that matches backscatter versus grazing angle as measured by the MBES to model predictions, thereby providing sediment properties.

However, not only acoustic characteristics are indicative for the sediment type, also natural radioactivity levels differ for different sediment types and can as such be used to discriminate between sediments. In this paper, radioactivity levels taken with the Multi-Element Detection System for Underwater Sediment Activity (Medusa), ${ }^{16,17}$ which takes measurements with a gamma-ray scintillation detector, are considered. The system measures gamma-rays being emitted from very low concentrations of a number of radionuclides in the sediment, viz. ${ }^{137} \mathrm{Cs},{ }^{40} \mathrm{~K}$, and radionuclides from the decay series of ${ }^{238} \mathrm{U}$ and ${ }^{232} \mathrm{Th}$. It is towed over the sediment bed behind the vessel. Due to the attenuation of gamma radiation in the sediment, the measured concentrations are characteristic for the top 30 to $50 \mathrm{~cm}$ of the sediment. In addition to the radionuclide concentration measurements, Medusa also takes measurements with a hydrophone towed over the sediment. These resulting noise levels can be used to determine whether or not the system is in contact with the sediment, but are also indicative for the sediment roughness. The measurements taken with the Medusa system and the corresponding data analysis are presented.

The aim of the research presented in this paper is twofold. (1) In general, the MBES sediment classification methods that classify sediments as a series of acoustic classes are relatively easy to implement and require limited computational efforts. This holds for the phenomenological approaches, but also for the Bayesian method of Ref. 14 . The drawback of these methods is that it is not always straightforward to assign sediment type or sediment parameters to the different acoustic classes. Still, this knowledge is considered of high importance for many applications. Therefore, in this paper, the results obtained by applying a model-based method are compared to those obtained with the method of Ref. 14 to investigate the relation between acoustic classes and sediment properties. The results illustrate that although the mean grain size is the most important parameter, the correlation coefficient between mean grain size and acoustic classes is limited, impeding a direct conversion of acoustic class to mean grain size. (2) Classification methods based on MBES data can discriminate only sediments that show acoustically distinct behavior. In this contribution, the acoustic classification results are compared with results of the completely independent Medusa method. The aim is to investigate if there is increased classification potential by using the data of these two independent data sources. The results show that the Medusa measurements and MBES measurements reveal a similar distribution of the different sediment types, thus providing confidence in the reliability of both independent methods. The low correlation between the acoustic classification results (classes and sediment parameters obtained from the model-based method) and concentration of ${ }^{137} \mathrm{Cs}$ indicates that complementary information can be derived from this radionuclide which is known to be a proxy for the fraction of organic matter.

This paper is organized as follows. In Sec. II, details about the experiment are given. Section III provides a brief description of the acoustic classification methods and the Medusa method. The classification results of each of the methods are presented in Sec. IV. Section V gives a comparison between the methods and discusses their similarities and differences. Finally, the main conclusions of the paper are summarized in Sec. VI.

\section{A DESCRIPTION OF THE MEASUREMENTS TAKEN IN THE DORDTSE KIL AREA}

The Dordtse Kil is a river in The Netherlands (South Holland) and is an important link and transport axis. The water depths in the Dordtse Kil as acquired by the MBES are presented in Fig. 1.

The river area was surveyed in October 2009 over a length of $\sim 10 \mathrm{~km}$ and its almost full width of $260 \mathrm{~m}$, using the EM3002D Kongsberg dual head MBES. The total number of beams is 320 (160 per head). The operation frequency was $300 \mathrm{kHz}$, the pulse length was $150 \mu \mathrm{s}$, and the maximum ping rate was $40 \mathrm{~Hz}$. The beam width was $1.5^{\circ} \times 1.5^{\circ}$. All beams were electronically stabilized for pitch and roll. For each beam and each ping a single backscatter value is given. This value is the result of first applying a moving average over the time series of amplitude values and then selecting the maximum average level of each beam. ${ }^{18}$

During the survey, measurements were taken with the Medusa system measuring the sediment natural radioactivity. This system is towed behind the vessel. For these measurements, contact between the sensor and the sediment is essential. To validate if indeed the sensor was located on the sediment, it is equipped also with a hydrophone. High noise levels indicate good contact between the sensor and the sediment, whereas low noise indicates that the sensor is floating in the water.

In addition, bottom grab samples were collected along the river. For each bottom grab sample the grain size distribution was determined. These results are shown in Fig. 2(a), illustrating unimodal behavior for all grab samples. The grab samples indicate mainly fine-grained sediments with mean grain sizes $M_{z}$ ranging from -0.15 to 5 in $\varphi$ units, with $M_{z}=-\log _{2}(d)$ and $d$ the mean grain size in $\mathrm{mm}$, see Fig. 2(b). 


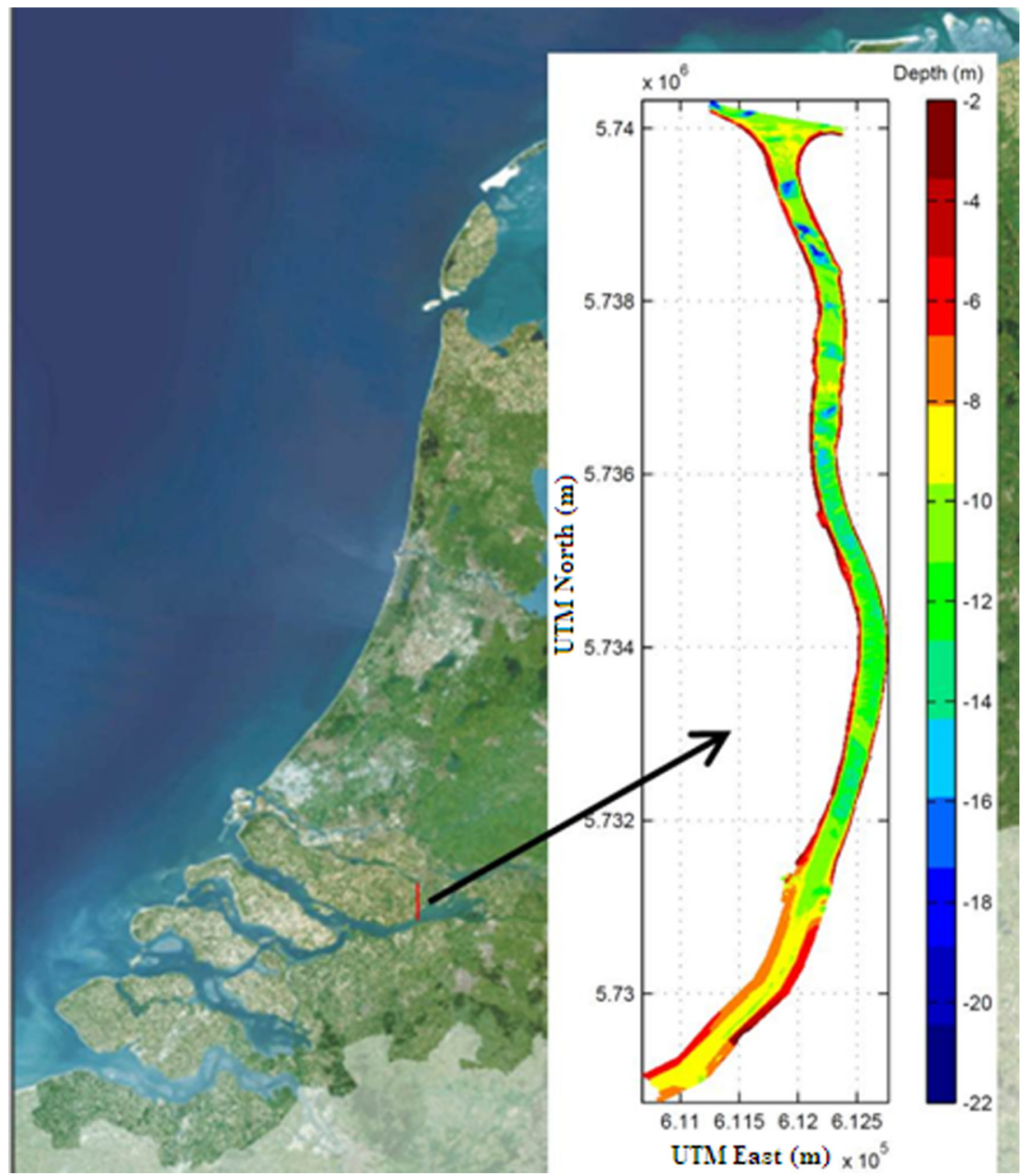

FIG. 1. (Color online) The bathymetry of the Dordtse Kil superimposed upon a view of The Netherlands.

\section{SEDIMENT CLASSIFICATION METHODS}

\section{A. The Bayesian classification method using MBES backscatter data}

In Ref. 14 a method is presented for sediment classification using MBES backscatter measurements. The method carries out the classification per angle, which makes it insensitive to variations in sediment type along the swath and to imperfect sonar calibration. It fits a number of Gaussian probability density functions (PDFs) to the histogram of the backscatter strength $(B S)$ data at a given angle, i.e.,

$$
B S \sim f_{B S}(B S)=\sum_{i=1}^{r} c_{i} N\left(B S ; \mu_{i}, \sigma_{i}^{2}\right),
$$

where $\mu_{i}$ and $\sigma_{i}^{2}$ are the mean and variance of the $i$ th Gaussian distribution $N$, respectively, and $c_{i}$ is the contribution of the individual Gaussian functions to the total PDF. $f_{B S}$ is the fitted histogram. The number of PDFs is increased until the chi-square distributed test-statistic of the residuals becomes less than a critical value. Based on the resulting $r$ Gaussian PDFs, the Bayes decision rule is applied to determine the $r$ regions of backscatter values corresponding to the $r$ acoustic classes.

The method is based on the assumption that the backscatter values for a single sediment type follow a Gaussian distribution for a sufficiently large number of scatter pixels in the beam footprint. For shallow river areas, Gaussianity of the distribution is ensured by averaging the measured backscatter values over surface patches, consisting of a small number of beams in the across-track direction and a few pings in the along-track direction. ${ }^{15}$ Bottom slopes are accounted for according to the method presented in Ref. 15.

\section{B. A model-based approach for sediment classification}

Whereas the Bayesian method makes use of the backscatter values per angle, alternatively use can be made of the complete backscatter curve, i.e., the backscatter as a function of angle. Models exist that predict these backscatter curves as a function of sediment properties and frequency. By searching for those sediment properties that result in an optimal agreement between modeled and measured backscatter curve, the sediments can be classified. In this case, the classification results consist of real sediment properties instead of acoustic classes. For the work presented in this paper, the model described in Ref. 19 is employed for predicting the backscatter curve. We hereby assume that the model, although developed for frequencies between 10 and $100 \mathrm{kHz}$, is still applicable for the current frequency of $300 \mathrm{kHz}$.

The total backscatter strength is expressed as a combination of the interface roughness scattering and volume scattering 
a)

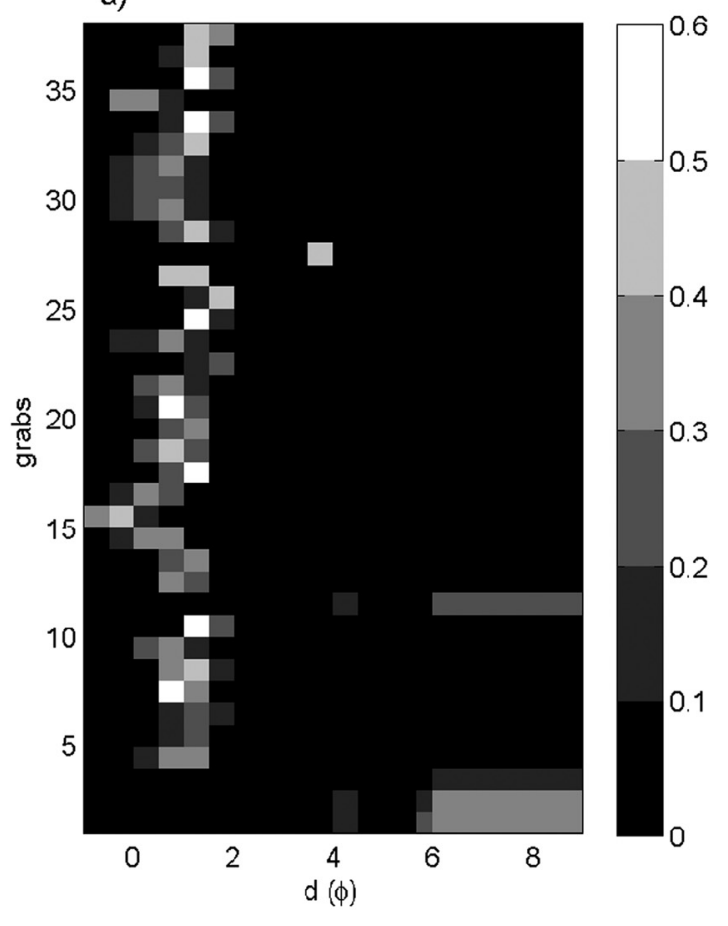

$$
B S(\theta)=10 \log _{10}\left(\sigma_{r}(\theta)+\sigma_{v}(\theta)\right)
$$

with $\sigma_{r}$ and $\sigma_{v}$ the backscattering cross sections due to the interface roughness and volume scattering, respectively. $\sigma_{r}$ is derived by an appropriate interpolation between three approximations: ${ }^{19}$

(1) the Kirchhoff approximation valid for fine to slightly coarse sediments and at grazing angles close to nadir;

(2) the composite roughness approximation appropriate for all other angles;

(3) for rough bottoms (e.g., gravel and rock) use is made of an empirical expression.

All three contributions are a function of the sediment roughness spectrum. An isotropic relief spectrum is assumed as $W_{2}(K)=\left(h_{0} K\right)^{-\gamma} w_{2}$, with $K$ the bottom relief wave number, $h_{0}$ a reference length $(1 \mathrm{~cm}), w_{2}$ the spectral strength and $\gamma$ the spectral exponent. Additionally, $\sigma_{r}$ is determined by the sediment density, attenuation coefficient, and sound speed.

$\sigma_{v}$ is modeled based on the following expression for the sediment volume backscattering cross section

$$
\sigma_{p \nu}=\frac{5 \delta \sigma_{2}\left|1-R^{2}(\theta)\right| \sin ^{2} \theta}{\nu \ln 10|P(\theta)|^{2} \operatorname{Im}(P(\theta))},
$$

where $\nu$ is the ratio of sediment to water sound speed, $\delta$ the ratio of imaginary to real wavenumber in the sediment, $R$ the amplitude reflection coefficient, $\theta$ the grazing angle, $\sigma_{2}$ the ratio of sediment volume scattering cross section to attenuation coefficient, and $P(\theta)=\sqrt{\kappa^{2}-\cos ^{2} \theta}$, with $\kappa=(1+i \delta) / \nu$. In addition to $\theta, R$ is also a function of the sediment parameters $\nu, \delta$ and $\rho$. The latter is the ratio of b)

FIG. 2. (a) Grab sample grain size distribution; (b) grab sample mean grain sizes.

sediment to water mass density. $\sigma_{v}$ is determined from $\sigma_{p v}$ accounting for shadowing and bottom slopes according to Ref. 19.

Empirical expressions exist that relate $\sigma_{2}, w_{2}, \rho, \nu$, and $\delta$ to mean grain size $M_{z} \cdot{ }^{19}$ However, values encountered for $w_{2}$ and $\sigma_{2}$ are known to often deviate significantly from the values obtained by the empirical expressions.

As a first step in assessing the agreement between model predictions and measured backscatter curves, backscatter curves measured close to locations of the grab samples are considered. The model is run for mean grain size values as determined from the grab samples, and values for all other model input parameters are derived from the empirical expressions relating them to the mean grain size. Differences (not shown here) between the resulting model predictions and measurements can be attributed to:

(1) sediment types that change along the swaths;

(2) values for the $\sigma_{2}, w_{2}, \rho, \nu$, and $\delta$ that deviate from those obtained from the empirical expressions;

(3) imperfect calibration of the MBES backscatter measurements.

To solve for these effects the following procedure is applied. An objective function is defined that quantifies the difference between the modeled and measured backscatter strength:

$$
f(\mathbf{x})=\sum_{\theta}\left|b_{i}^{m e}(\theta)-b_{i}^{m o}(\theta ; \mathbf{x})\right|,
$$

where $b_{i}^{m e}$ and $b_{i}^{m o}$ are the measured and modeled backscatter strength for the $i$ th grab, respectively. The use of Eq. (4), providing a measure for the absolute discrepancies between the measured and modeled backscatter curves based on the 
L1 norm, is motivated due to its robustness property compared to the ordinary least-squares (L2) norm. ${ }^{20}$ In general, $\sigma_{2}$ and $w_{2}$ are known to show the largest deviations from the empirical predictions and, therefore, these parameters are considered as unknowns, contained in vector $\mathbf{x}$. An estimate for the mean grain size is available from the grab samples, but still this parameter is allowed to vary slightly. Consequently, $\mathbf{x}$ contains three unknowns, i.e., $\sigma_{2}, M_{z}$, and $w_{2}$. For minimizing Eq. (4), use is made of the differential evolution method as described in Refs. 21 and 22.

Due to the imperfect calibration of the MBES and the noise of the measurements, the objective function will not become zero. The average curve of the differences (between measured and modeled curves) for all grab samples can be considered as the calibration curve. However, as mentioned in item 1 above, measurements can also be affected by variations in sediment types along the swath. Accounting for these measurements will result in differences between modeled and measured backscatter curves that differ significantly from the average, i.e., the calibration curve.

Therefore, an iterative procedure is followed to establish the final calibration curve. In each iteration the measurements are corrected using the calibration curve of the previous iteration. The measurement with maximum discrepancy with the mean curve is masked as an outlier. A new calibration curve is then determined, based on the remaining measurements, as the sum of the old curve and a correction to this curve. After removing more and more outliers, at some iteration the discrepancies become negligible and no further corrections on the calibration curve are required.

The final calibration curve is then applied to all measured backscatter curves, allowing for determination of the three parameters $M_{z}, w_{2}$, and $\sigma_{2}$ over the entire area.

\section{Medusa method}

The Medusa system takes measurements with scintillator-based gamma-ray detectors, towed over the sediment. These measurements allow for: (a) measurement of natural background radiation, and (b) absolute measurement of radionuclide concentrations in the sediment through deconvolution of the measured signal's spectrum. ${ }^{23}$ The deconvolution focuses on estimating concentrations of the radionuclides ${ }^{238} \mathrm{U},{ }^{232} \mathrm{Th},{ }^{40} \mathrm{~K}$, and ${ }^{137} \mathrm{Cs}$, since these are known to be indicative for the sediment properties: silt content, organic matter content and mean grain size.

\section{Measuring silt content}

The ${ }^{238} \mathrm{U}$ uranium occurs naturally in trace amounts in sediments by its incorporation in silt, sand and in some heavy minerals. In the Netherlands, typical concentrations in silt are higher than in sand. The ${ }^{232}$ Th thorium isotope is also present in sediments in approximately similar concentrations in silt and sand. ${ }^{16}$ This makes uranium and thorium suited proxies for mapping silt and sand ratio's in the sediment. The correlation between uranium, thorium and silt content varies on the scale of a sedimentary basin. Grab sample investigations have shown that these correlations are similar for a delta system as large as the Netherlands. ${ }^{17}$

\section{Measuring organic matter content}

There is a distinct difference between the natural radionuclides $\left({ }^{40} \mathrm{~K},{ }^{238} \mathrm{U},{ }^{232} \mathrm{Th}\right)$ and ${ }^{137} \mathrm{Cs}$ in the way they are distributed in sediments. The natural radionuclides will at least initially be a more or less integral part of the minerals comprising the sediment while ${ }^{137} \mathrm{Cs}$ is a later surface addition that has been distributed in the environment by atmospheric testing of nuclear weapons in the 1960s and by the Chernobyl accident. The ${ }^{137} \mathrm{Cs}$ from Chernobyl has been preferentially deposited along a $150 \mathrm{~km}$ broad strip in northwest-southeast direction passing over the center of the Netherlands. The initially mobile ${ }^{137} \mathrm{Cs}$ is absorbed by silt and organic matter. ${ }^{17}$ This makes ${ }^{137} \mathrm{Cs}$ a proxy for the organic matter content of the sediments. The correlation between ${ }^{137} \mathrm{Cs}$ and organic matter depends strongly on the trends in deposition of ${ }^{137} \mathrm{Cs}$ during the Chernobyl fallout.

\section{Measuring grain size}

Coarse-grained sediments consist of a mixture of quartz and potassium feldspar. In the process of weathering, feldspars tend to be reduced in size during abrasion, while quartz tends to be fragmented and destroyed. ${ }^{24}$ This process will cause an increased concentration of feldspar in finer sediments and, consequently, a correlation between the concentration of feldspar and grain size. The Potassium feldspar minerals contain ${ }^{40} \mathrm{~K}$. Hence, the ${ }^{40} \mathrm{~K}$ concentration can be used as grain size indicator. The exact relation between the ${ }^{40} \mathrm{~K}$ concentration and mean grain size depends on the location.

The concentration of radioactive nuclides in a specific type of sediment is called the radiometric fingerprint of that sediment. To derive a fingerprint for the sediments in a certain area use is made of grab samples taken in the area. These grab samples are analyzed both with respect to their sediment properties and the radionuclide concentrations. Based on the resulting relations between the sediment properties and radionuclide concentrations, the radioactive emissions measured by Medusa over the area can be converted to maps of the sediment properties.

In addition to the radiometric measurements, the Medusa system is also equipped with a hydrophone. This hydrophone is towed over the sediment surface with the primary purpose to check whether the Medusa system touches the sediment, resulting in high noise levels, or is floating freely in the water, corresponding to much lower measured noise levels. From experience, it is found that these hydrophone measurements can also be used to assess sediment roughness and the presence of features, such as shells, on the sediment.

\section{CLASSIFICATION RESULTS}

\section{A. Applying the Bayesian method for classifying the Dordtse Kil sediments}

Surface patches were created by averaging over approximately eight beams and five pings. The average distance between two consecutive beams is $15 \mathrm{~cm}$ and between two pings is $25 \mathrm{~cm}$, and consequently each surface patch is 

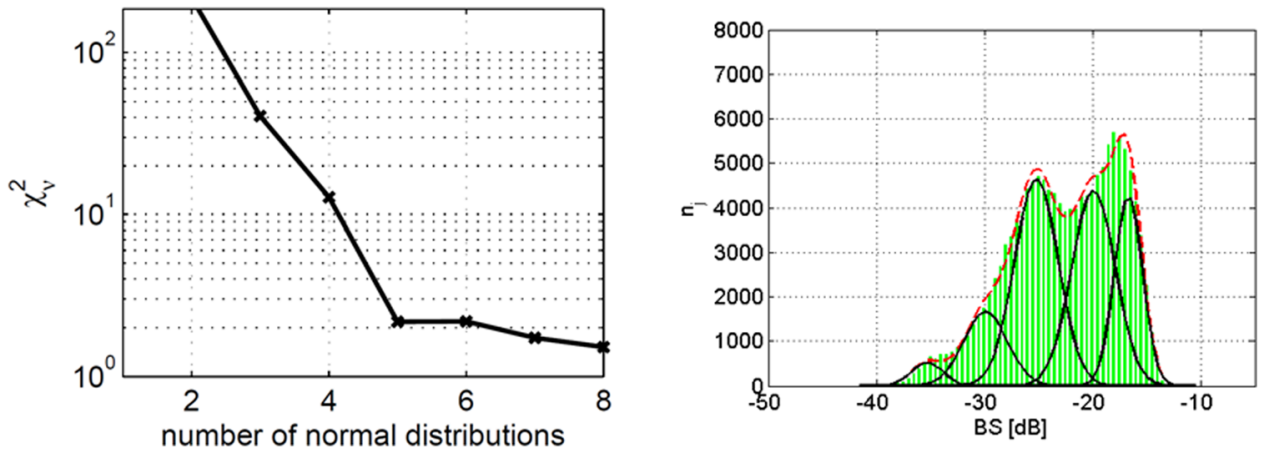

FIG. 3. (Color online) Normalized chi-square distributed test statistic versus number of classes (left frame). The right frame presents the histograms of the measured BS data, i.e., number of measurements $n_{j}$ as a function of BS, over the entire area (bars), the five Gaussians (solid lines), and its best fit (dashed line) at a grazing angle of $30^{\circ}$ (right frame).

approximately of size $120 \mathrm{~cm} \times 125 \mathrm{~cm}$. After applying corrections for the bottom slope, the average backscatter strength was determined for each of the patches. The assumption of a Gaussian distribution for the backscatter PDFs was tested for areas with a single sediment type and was found to be valid.

From the test statistic, it is observed that the optimal value for the number of classes amounts to five, as illustrated in the left frame of Fig. 3, since more classes do not result in a significantly better agreement between model and measurements. The obtained model contains sufficient detail for describing the measurements. The right frame shows the histogram and the Gaussian fit for the averaged backscatter values at the grazing angle of $30^{\circ}$ for the left transducer. A similar approach, fitting the histogram with a number of Gaussians, is taken for all other angles, providing for each angle the range of backscatter values corresponding to each of the classes. However, since the discriminative performance is best for the most grazing angles, $\sim 30^{\circ}$ in this case, due to their large beam footprint, the number of classes as derived for this angle, i.e., five, is used for the fitting procedure for the other angles. The classification map of the area obtained by accounting for the full range of usable angles $\left(26^{\circ}-70^{\circ}\right.$ grazing angles) is presented in Fig. 4.

\section{B. Model-based results}

The strategy explained in Sec. III B is now applied to the MBES data acquired in the Dordtse Kil. For all MBES tracks that were sailed over the 38 grab sample positions, mean backscatter curves are obtained over a few consecutive pings. This resulted in 73 combinations of grab samples and mean backscatter curves, as grab sample locations were crossed multiple times while taken the MBES measurements. These curves and the $M_{z}$ values of the corresponding grab samples are used to derive the calibration curve. The results are illustrated in Fig. 5. The bottom sub-frame at the left shows the (minimized) differences between modeled and observed backscatter curves when accounting for all grab samples. In an ideal case the differences are identical and hence represent the final calibration curve. However, due to variations in sediment type along the swathes and measurement noise, an ideal curve can never be obtained. Therefore the median curve of the differences is considered to be a first estimate for the calibration curve (thick black line in the left bottom frame of Fig. 5). Due to the robustness of the L1 norm minimization, the results presented are not affected by possible outliers. Still, the quality of the estimated calibration curve can be improved by removing some of the outliers. Therefore, the iterative approach of Sec. III B is applied. The approach was stopped after nine iterations after

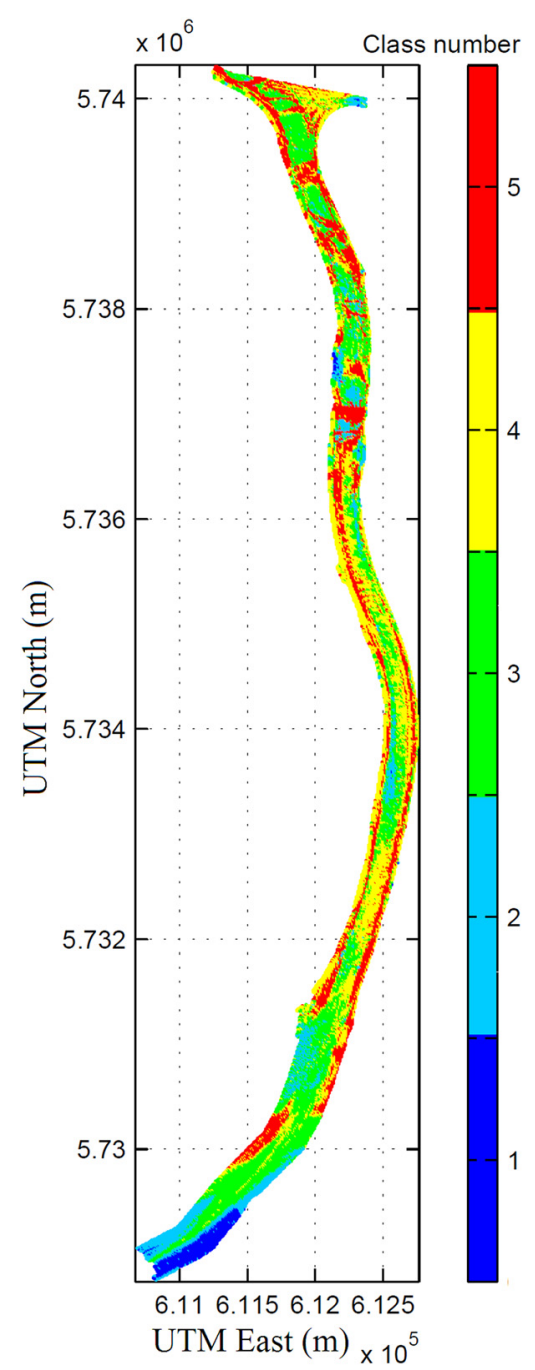

FIG. 4. (Color online) Classification of the Dordtse Kil river obtained by applying the Bayesian acoustic classification method. 

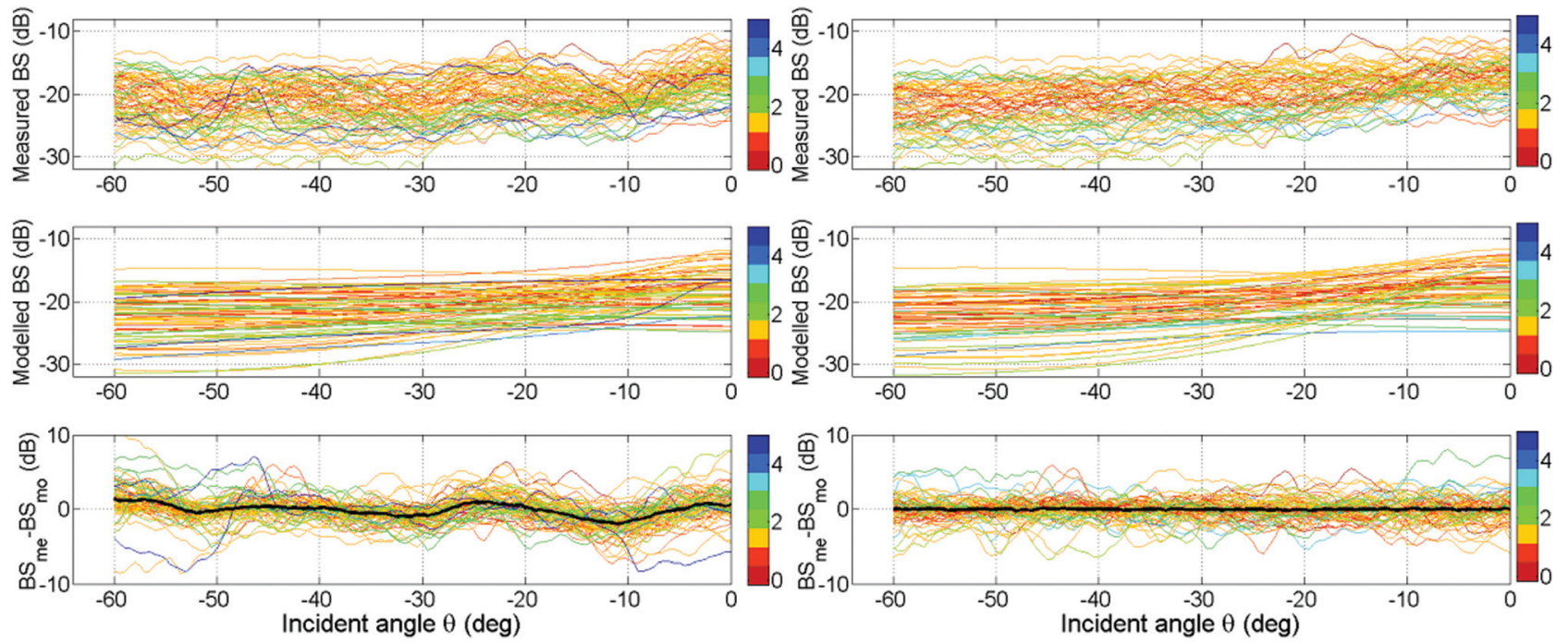

FIG. 5. Measured backscatter as a function of grazing angle $\theta$ at grab sample positions (top sub-frames), corresponding modeled backscatter versus $\theta$ (middle sub-frames) and difference between modeled and measured backscatter versus $\theta$ (bottom sub-frame). The left frames show the result at the first iteration, with all grab samples accounted for. The thick black line in the left bottom sub-frame is the mean of the differences between modeled and measured backscatter, representing the initial calibration curve. The right frames show the result at the final iteration. The measurements (top sub-frame) have been corrected using the calibration curve corresponding to the ninth iteration. The thick black line in the right bottom sub-frame indicates the corrections that would be applied in the next iteration. Colors indicate mean grain sizes in phi unit.

which the L1 norm has decreased from over $80 \mathrm{~dB}$ to $\sim 5 \mathrm{~dB}$. Additional iterations did not result in a further decrease. It was found that for three grab samples, with mean grain sizes of $1.3,1.5$, and $5.0 \varphi$, all combinations of these grab samples and backscatter curves were identified as outlier. This can be caused by errors in the measurements, for example due to uncertainties in the exact grab sample locations or backscatter curves that are affected by variations of sediment type along the swath, but can also be due to the backscatter model output not being representative for the sediment at the locations of the grab samples.

The results from the iterative approach are presented in the right frame of Fig. 5.

In the next step, the calibration curve is used to correct all measured backscatter curves, obtained by averaging over a few consecutive pings. These are then fed into the optimization process where a search is performed to determine values for $\sigma_{2}, M_{z}$, and $w_{2}$ that provide a maximum agreement between modeled and measured backscatter curve from Eq. (4). The search bounds were selected as $-1 \leq M_{z} \leq 9$, $5 \times 10^{-5} \leq w_{2} \leq 2 \times 10^{-2}$, and $5 \times 10^{-5} \leq \sigma_{2} \leq 5 \times 10^{-3}$. Figure 6 shows two typical examples where this inversion has been applied. The modeled curves fit the measured curves quite well indicating a reliable optimization method and processing strategy.

Empirical relations between $M_{z}, w_{2}$, and $\sigma_{2}$ are provided in Ref. 19. For $-1 \leq M_{z}<5$, the relation between $M_{z}$ and $w_{2}$ is

$$
w_{2}=0.00207 h^{2} \quad \text { with } h=\frac{2.03846-0.26923 M_{z}}{1+0.076923 M_{z}} .
$$

For $5 \leq M_{z} \leq 9$ the interface roughness parameter is $w_{2}=0.00207 h^{2}$, where $h=0.5$. With regard to $\sigma_{2}$, Ref. 19
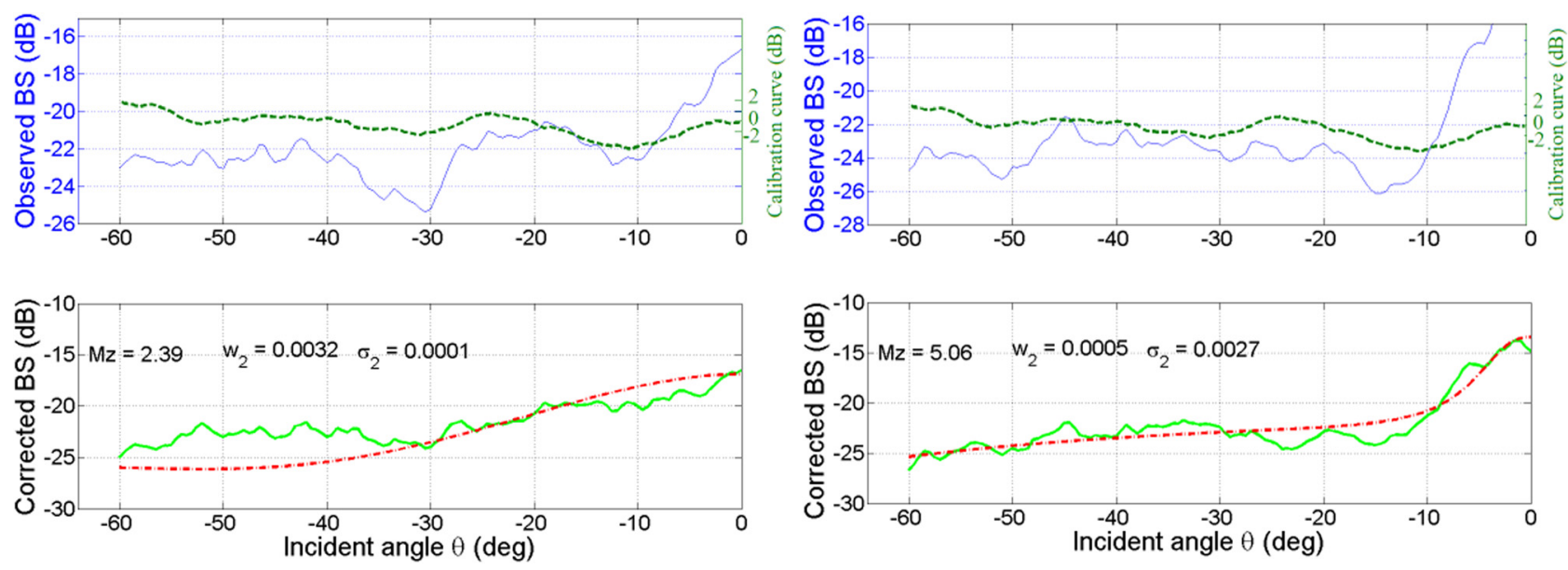

FIG. 6. (Color online) Two examples of the optimization problem where the three parameters $M_{z}, w_{2}$, and $\sigma_{2}$ are searched for. In each frame the top sub-frame is the calibration curve (thick dashed line) and the observed backscatter curve (thin solid line). The bottom sub-frame is the corrected (thick solid line) and modeled (thick dashed-dotted line) backscatter curve. Indicated in the plots are the estimated parameters for each inversion. 


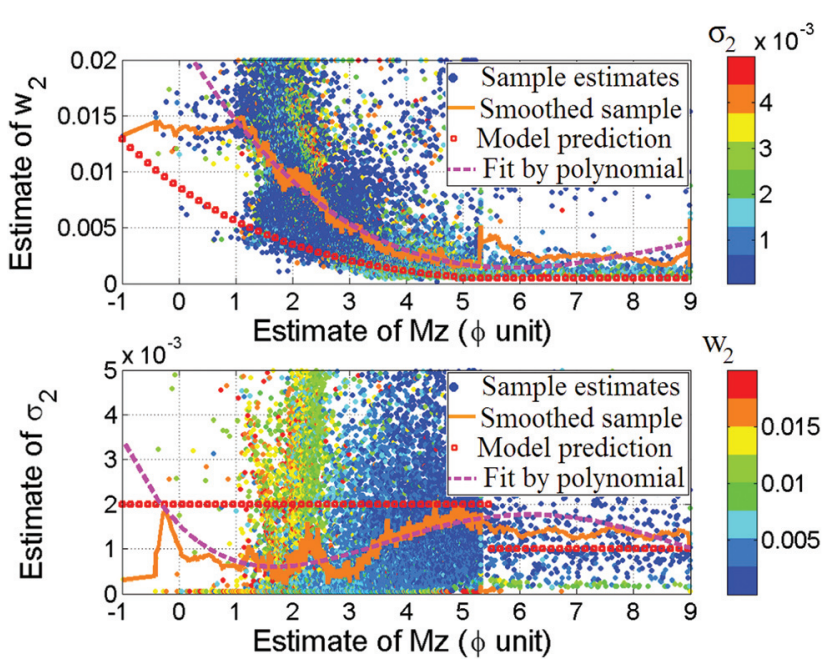

FIG. 7. Estimated (dots) $w_{2}$ versus $M_{z}$ (top) and $\sigma_{2}$ versus $M_{z}$ (bottom). The two frames also show respectively the values of $w_{2}$ and $\sigma_{2}$ predicted by empirical models (squares), their moving averages (smoothed), and third-order polynomial best fit. In each subplot colors indicate the third estimated parameter, i.e., $\sigma_{2}$ (top) and $w_{2}$ (bottom).

indicates a value of $\sigma_{2}=0.002$ for $-1 \leq M_{z}<5.5$ and $\sigma_{2}=0.001$ for $5.5 \leq M_{z}<9$, respectively.

Figure 7 presents both the estimates for $w_{2}$ and $\sigma_{2}$ versus $M_{z}$ as obtained from the inversions and predicted from the empirical expressions. It can be seen that, in general, the $w_{2}$ values obtained from the inversions are a factor of 2 higher than those predicted by the empirical model. A reverse situation holds for $\sigma_{2}$, where values of $\sigma_{2}$ determined from the inversions are a factor 2 lower that those predicted by the empirical expressions for $-1 \leq M_{z}<5.5$. However, the estimates for $\sigma_{2}$ show a large spread, indicating limited sensitivity of the problem to this parameter. This is at least partly due to the high frequencies considered. Another observation is that a discontinuity exists in the behavior of the estimates for $\sigma_{2}$ at $M_{z}=5.3$. At $M_{z}=5.3$, the empirical relations expressing $\nu$, i.e., the ratio of sediment to water sound speed, and $\rho$, which is the ratio of sediment to water mass density, as a function of $M_{z}$, change. This might indicate that these relations require corrections when used for the frequency of $300 \mathrm{kHz}$ as considered here.

Finally, Fig. 8 presents the estimated values for $M_{z}, w_{2}$, and $\sigma_{2}$ as a function of position, where for illustrative purposes logarithm scales are used to present $w_{2}$ and $\sigma_{2}$. The three maps clearly show areas differencing in sediment types. In general, the three parameters reveal similar spatial patterns. The $M_{z}$ values indicate that the softest sediment belongs to the southern part of the Dordtse Kil river. Values for the inverted parameters are found to be at the search bounds for certain areas in the southern part. These results are not included in Fig. 8 as the inversion is considered not successful. Since these results are found in distinct regions, i.e., the gaps in the Fig. 8 maps as indicated by arrows, we hypothesize that for these regions the backscatter model output is not representative for the sediments of those areas.
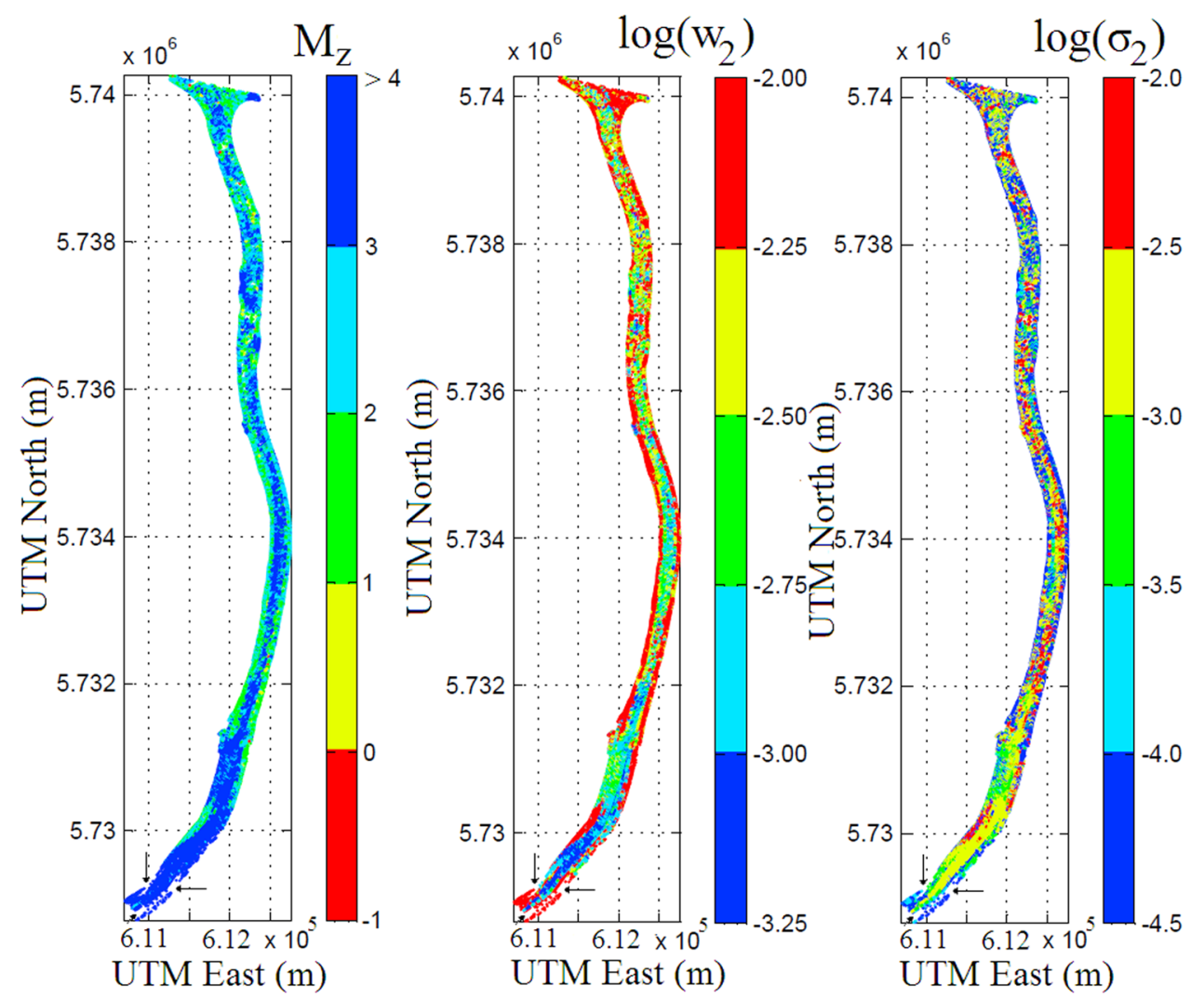

FIG. 8. (Color online) Maps of inverted mean grain size $M_{z}$ (left frame), spectral strength $w_{2}$ (middle frame), and volume scattering parameter $\sigma_{2}$ (right frame). Arrows indicate the regions for which the inversions converged to values for $M_{z}, w_{2}$, or $\sigma_{2}$ that are at the bound of the search regions. 

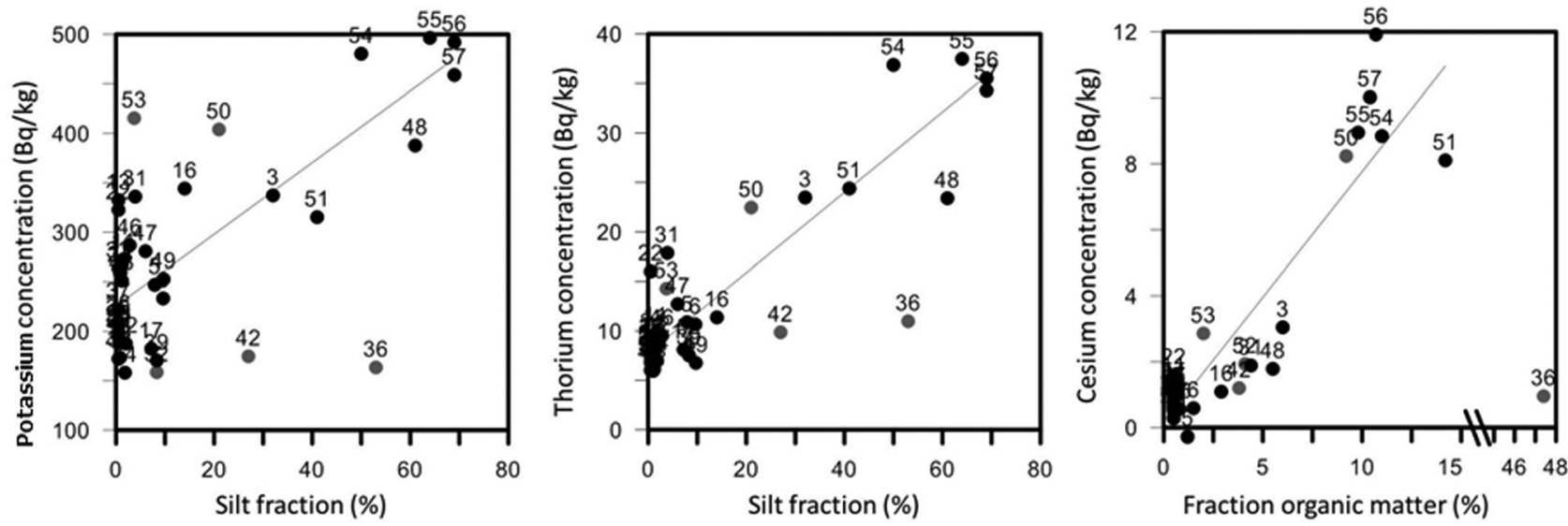

FIG. 9. ${ }^{40} \mathrm{~K}$ and ${ }^{232} \mathrm{Th}$ versus silt fraction and ${ }^{137} \mathrm{Cs}$ versus the fraction of organic matter. The grab samples with low correlation are indicated with gray dots.

\section{Medusa results}

The total activity of the nuclides was determined by spectrum deconvolution on the measured signal. ${ }^{23}$ The activity concentrations in the grab samples were then determined by the measured activity divided by the mass of the grab sample and the dry matter percentage. The dry matter percentage was determined by the moisture loss in $6 \mathrm{~h}$ at a temperature of $130{ }^{\circ} \mathrm{C}$. The silt fraction and organic matter content as determined from the grab samples were compared to the concentrations of ${ }^{232} \mathrm{Th},{ }^{40} \mathrm{~K},{ }^{238} \mathrm{U}$, and ${ }^{137} \mathrm{Cs}$. It was found that the ${ }^{232} \mathrm{Th}$ and ${ }^{40} \mathrm{~K}$ concentrations show positive correlation with the silt fraction. No significant correlation was found with ${ }^{238} \mathrm{U}$. Furthermore, a significant correlation exists between ${ }^{137} \mathrm{Cs}$ and the fraction of organic matter in the grab samples. Both are illustrated in Fig. 9. The resulting maps for the silt fraction, as derived from the ${ }^{232} \mathrm{Th}$ and ${ }^{40} \mathrm{~K}$ concentrations, and organic matter (from ${ }^{137} \mathrm{Cs}$ concentrations) are presented in Fig. 11 (right and center frames).

Since the ${ }^{40} \mathrm{~K}$ concentrations were found to show the strongest correlation with the mean grain size (80\%), for the current study this parameter was finally used as a predictor of the grain size, $d_{50}$, denoting the grain size at which $50 \%$ of the sediments in the grab sample are smaller. This strong correlation is illustrated in Fig. 10.

The following relation between ${ }^{40} \mathrm{~K}$ concentration $K$ and $d_{50}$ was established by linear regression

$$
d_{50}=-0.54 K+425.5
$$

with a coefficient of determination $\left(\mathrm{R}^{2}\right)$ of 0.8 . The grab samples indicated as gray dots in Fig. 10 were not accounted for in deriving the above relation as they contain some peat, shells, or wood that were removed when determining the radionuclide concentrations, but were accounted for in the mean grain size determination.

By using Eq. (6), a mean grain size map of the full area was derived based on the ${ }^{40} \mathrm{~K}$ concentrations that were measured during the survey, the results of which are presented in Fig. 11 (left frame). Note that since the grab sample positions are not coincident with the Medusa tracks, the range of mean grain sizes encountered in the grab samples differs from the range derived with the Medusa system towed over the sediment. Especially the grab samples corresponding to the smallest mean grain sizes were taken at locations where no measurements were taken with the towed Medusa sensor. All plots contained in Fig. 11 have been obtained by Kriging interpolation ${ }^{25}$ of the data as acquired along the tracks.

The results of the measurements as taken by the Medusa hydrophone that is towed over the sediment surface, are presented in Fig. 12. Their primary use is to indicate whether the Medusa system touches the sediment, or floats freely in the water. However, these measurements are also indicative of the roughness of the sediment, where high noise is associated with rough boundaries and low noise is associated with smooth boundaries. Since the hydrophone is not calibrated, the measured noise intensities can only be used in a relative manner to assess variations in roughness over an area.

\section{COMPARISON AND DISCUSSION}

In Fig. 12 an overview of the results of applying the methods for sediment classification described in the previous sections is presented, partly repeating the plots presented in Sec. IV. To allow for comparison, this figure presents only those results that are directly related to the sediment mean

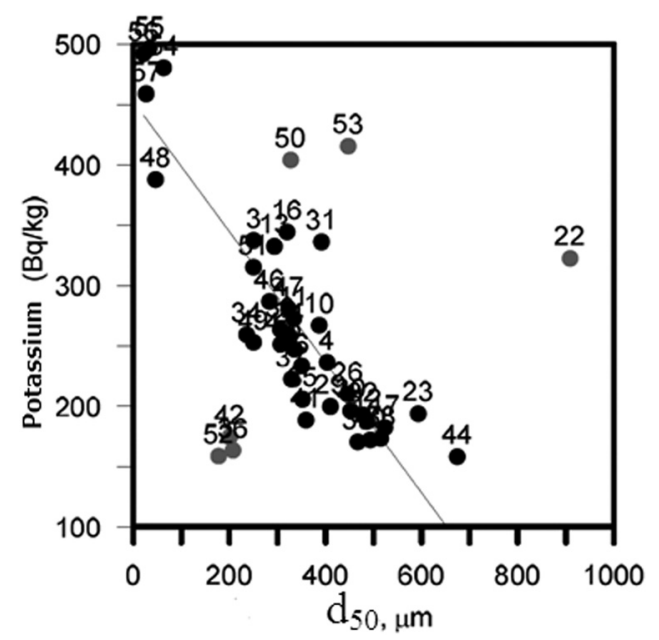

FIG. 10. ${ }^{40} \mathrm{~K}$ concentration versus $d_{50}$ for the grab samples taken in the area. The numbers indicate numbers of the grab samples. The grab samples with low correlation are indicated with gray dots. 

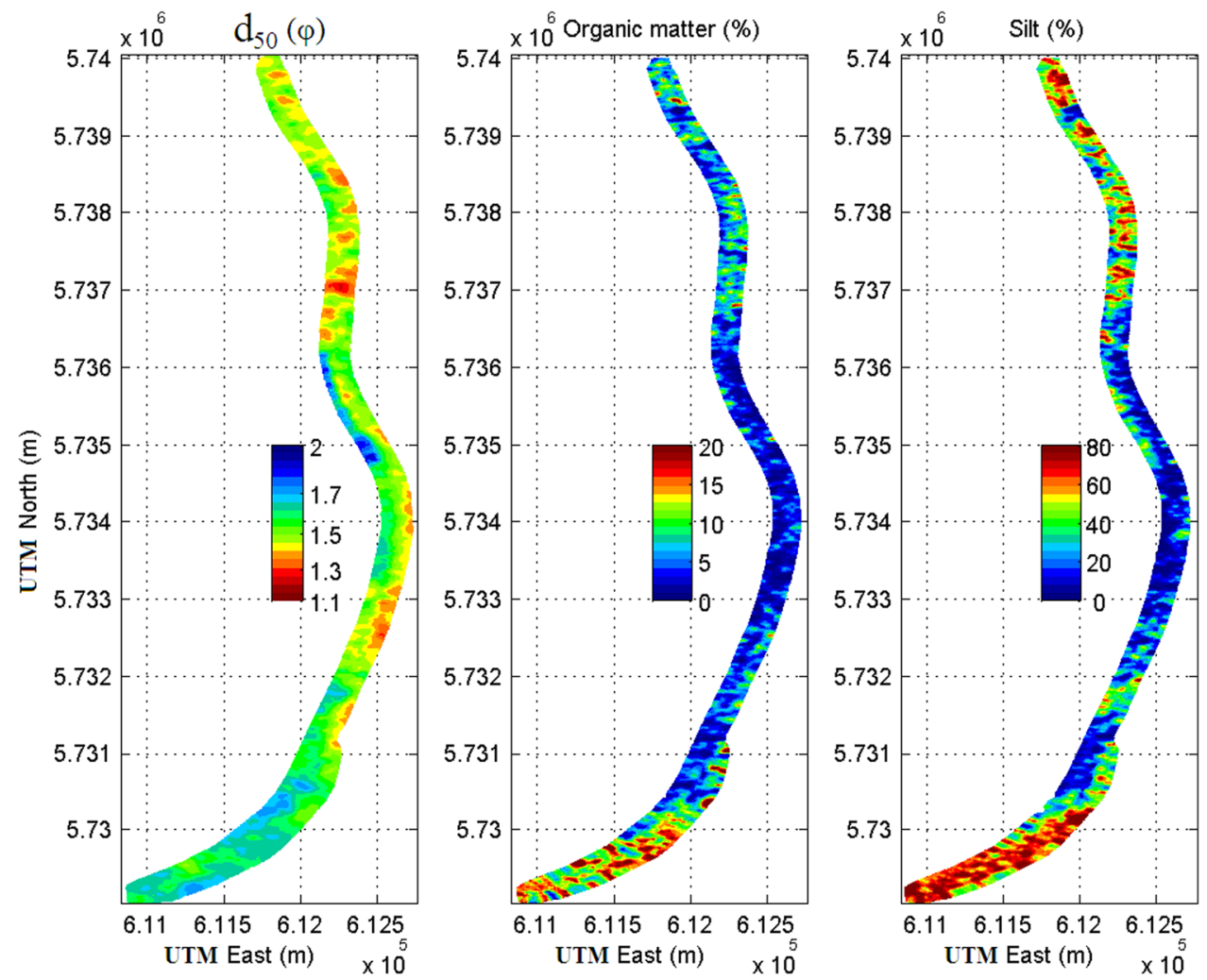

FIG. 11. (Color online) Maps of the $d_{50}$ (left) values (in $\varphi$ units), organic matter (middle), and silt fraction (right) in Dordtse Kil using the Medusa method.

grain size. Therefore, the estimates of silt fraction and organic matter are not included. To ease the comparison, similar colormaps are used for all five maps, where blue corresponds to the finer sediment and red to the coarsest sediment. It should be noted that the Medusa measurements were taken only along six lines in the middle of the river with an average distance of $40 \mathrm{~m}$ between lines; no measurements are taken at the border of the river, resulting in a low spatial resolution compared to the MBES results. (Note that for the unimodal sediment grain size distribution encountered (Fig. 2), differences between $M_{z}$ based on $d_{50}$ [obtained from the Medusa measurements through Eq. (6)] and $M_{z}$ based on $d$ [grab samples and model-based method) are negligible $(<0.3 \varphi)$ ].

Despite the differences in the range of mean grain size values as obtained for the different methods, with, for example, the model-based results showing an overestimation of $M_{z}$ compared to the grab samples, we do observe a similar spatial pattern in the sediment distribution as revealed by all methods. Grain sizes are decreasing towards the southern

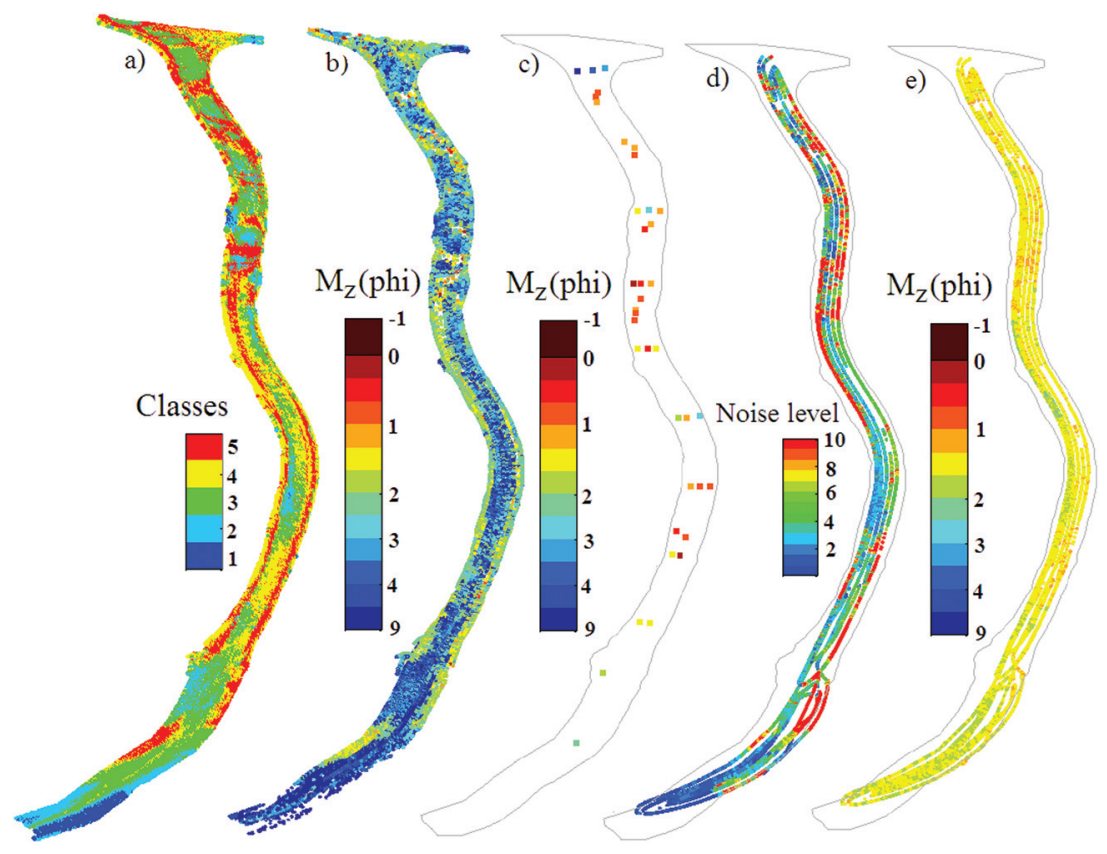

FIG. 12. Classification maps of Dordtse Kil river using different methods; acoustic classes of the Bayesian method (a), mean grain sizes in phi unit of the model based method (b), mean grain sizes in phi unit of the grab samples (c), noise received by the Medusa hydrophone (logarithmic scale) (d), and the mean grain size in phi unit using the Medusa method (e). 
part of the river, indicated both by the MBES model-based results and the grab sample analysis. Also the $M_{z}$ values derived from the ${ }^{40} \mathrm{~K}$ concentrations indicate finer sediments than on the remainder of the river. The Bayesian classification indicates the presence of the first two classes in the areas, corresponding to the lower backscatter strength values. It can also be seen that the noise levels measured with the Medusa hydrophone are low, indicating a smooth sediment surface as expected for these fine-grained sediments.

For the area north of this small grain size region, the Bayesian and model-based MBES results, along with the Medusa noise measurements, reveal that the middle of the river is mainly fine-grained, interspaced with areas containing coarser sediments. These results indicate coarser sediments also for the border of the river. The grab samples also indicate coarser sediments compared to the southern area, but their limited spatial sampling prevents derivation of more details regarding the sediment distribution. Although the ${ }^{40} \mathrm{~K}$ concentrations indicate coarser sediments compared to the south, these results differ from the other methods as the map based on the ${ }^{40} \mathrm{~K}$ concentration indicates areas with smaller grain sizes in the west of the middle part of the river which is not confirmed by any of the other methods.

In order to quantitatively assess the correspondence between all measured parameters, Fig. 13 presents the cross correlation matrix, where colors indicate the absolute values of the correlation coefficients between the classifiers obtained for all methods considered. All correlation coefficients, except those with the mean grain size from the grab samples, are based on at least 5000 locations, resulting in high confidence levels $(100 \%)$ for the correlation coefficients. Due to the limited amount of grab samples, correlation coefficients with the grab sample mean grain sizes are subject to lower confidence levels. Only those correlation

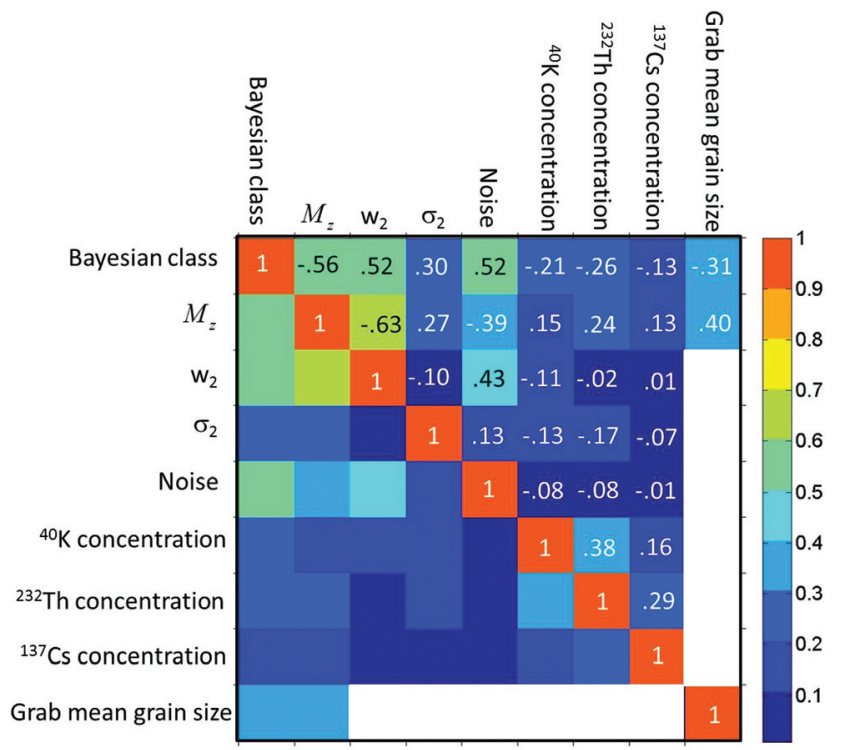

FIG. 13. Correlation coefficients (the colors indicate the absolute values) between Bayesian classes, the parameters obtained from the model-based method $\left(M_{z}, w_{2}\right.$, and $\left.\sigma_{2}\right)$, the parameters measured by the Medusa system (noise, ${ }^{40} \mathrm{~K}$ concentration, ${ }^{232} \mathrm{Th}$ concentration, and ${ }^{137} \mathrm{Cs}$ concentration) and the grab sample mean grain sizes. Only correlation coefficients with confidence levels exceeding $90 \%$ are indicated. coefficients with confidence levels exceeding $90 \%$ are presented in Fig. 13. (A confidence level of $90 \%$ means that there is a $10 \%$ probability that this correlation coefficient occurs fully by chance.)

From the correlations presented, it can be concluded that when considering the Bayesian classes, the highest correlation $(-0.56)$ is found between classes and the mean grain sizes as estimated from the model-based method. This limited correlation coefficient can be caused by a non-linear relation between mean grain size and acoustic classes, but can also be due to the fact that, in addition to sediment mean grain size, also parameters such as the volume scattering parameter and the sediment roughness contribute to the measured backscatter strengths. This impedes the use of a linear relation between acoustic classes and mean grain sizes, for example to convert a map presenting acoustic classes to a map of mean grain sizes. This is also demonstrated by the limited correlation coefficient between the Bayesian classes and the $M_{z}$ values of the grab samples $(-0.31)$.

From the Medusa measurements, the noise level is found to have the highest correlation with the Bayesian classes. The concentration of ${ }^{137} \mathrm{Cs}$ shows the lowest correlations. From Sec. IV C it is known that ${ }^{137} \mathrm{Cs}$ is highly correlated to the concentration of organic matter. Hence, the low correlation between ${ }^{137} \mathrm{Cs}$ and the acoustic classes is an indication that the presence of organic matter is not revealed by the Bayesian approach. The limited correlation with ${ }^{40} \mathrm{~K}$ and ${ }^{232} \mathrm{Th}$ with all other parameters, reflects the previous observation (based on Fig. 12) that in part of the area, the Medusa mean grain sizes show a spatial pattern that is not conformed by the other methods.

The substantial correlation of 0.43 between the noise levels measured by the Medusa hydrophone and the modelbased parameter $w_{2}$ results from the fact that both parameters are representative for the sediment surface roughness.

\section{SUMMARY AND CONCLUSIONS}

In this paper three methods for classification of sediments in the Dordtse Kil river in the Netherlands are presented. Two methods base the classification on MBES backscatter data, whereas the third method bases the classification on natural radioactivity. The first method uses the MBES backscatter data collected at a certain angle to obtain the number of acoustic classes and to discriminate between them by applying the Bayes decision rule for multiple hypotheses. The second method is model-based and matches the full measured backscatter versus angle curve of the MBES to the predicted backscatter curve using the model of Ref. 19. The third method, Medusa, bases the classification on measurements of gamma-ray radiation being emitted from very low concentrations of a number of radionuclides in the sediment, i.e., ${ }^{137} \mathrm{Cs},{ }^{40} \mathrm{~K},{ }^{238} \mathrm{U}$, and ${ }^{232} \mathrm{Th}$.

The Bayesian method provides acoustic classes, and is considered to be simple in principle and easy and fast to implement. For the Dordtse Kil area, the Bayesian method identified five acoustic classes. The model-based method provided the sediment parameters mean grain size $\left(M_{z}\right)$, spectral strength of sediment surface roughness $\left(w_{2}\right)$ and 
volume scattering parameter $\left(\sigma_{2}\right)$. By comparing the classes derived from the Bayesian method and the model-based results, it is found that the model-based mean grain size shows the highest correlation with the acoustic classes. However, this correlation is limited to -0.56 . This is an important result, as it indicates the limitations in the potential of using only (grab sample-based) mean grain size for assigning sediment parameters to the acoustic classes. The latter is also illustrated by the limited correlation coefficient $(-0.31)$ between the acoustic classes and the mean grain sizes obtained from grab samples.

The use of model-based methods would eliminate the above-mentioned limitations in converting acoustic class to sediment parameters. However, the model-based results indicate an overestimation of the $M_{z}$ values, i.e., too small mean grain size values. This can be due to a still imperfect calibration of the measured backscatter values, caused by a limited number of grab samples available for the calibration. In addition, imperfect modeling of the backscatter curve can play a role. These effects hamper the use of model-based methods for sediment classification.

Analysis of the data taken by the Medusa system provided estimates of the mean grain size based on the concentrations of ${ }^{40} \mathrm{~K}$ and estimates for the silt fraction based on ${ }^{40} \mathrm{~K}$ and ${ }^{232} \mathrm{Th}$. Furthermore, concentrations of ${ }^{137} \mathrm{Cs}$ were used as a predictor for the fraction of organic matter. In addition, noise levels were measured by a hydrophone towed over the sediments. The significant correlation between the Medusa noise level and $w_{2}$ indicate that the Medusa noise levels contain information about the sediment roughness. The low correlation between the ${ }^{137} \mathrm{Cs}$ concentrations and the Bayesian classification results indicates that backscatter measurements do not reveal the presence of organic matter. The Medusa system, however, can provide this information based on the ${ }^{137} \mathrm{Cs}$ measurements.

\section{ACKNOWLEDGMENTS}

The research is financially supported by Deltares. We acknowledge in particular Dr. Arjan Sieben, Ir. Ben Dierikx, Adri Wagener, and Dr. Erik Mosselman for their valuable contribution. We would also like to thank the associate editor and two anonymous reviewers for their constructive comments which improved the quality of the paper.

${ }^{1}$ C. de Moustier, "Beyond bathymetry: Mapping acoustic backscattering from the deep seafloor with Sea Beam," J. Acoust. Soc. Am. 79(2), 316-331 (1986).

${ }^{2}$ J. E. Hughes Clarke, "Toward remote seafloor classification using the angular response of acoustic backscattering: a case study from multiple overlapping GLORIA data," IEEE J. Ocean Eng. 19(1), 112-126 (1994).

${ }^{3}$ L. Hellequin, J. Boucher, and X. Lurton, "Processing of high-frequency multibeam echo sounder data for seafloor characterization," IEEE J. Ocean Eng. 28(1), 78-89 (2003).

${ }^{4}$ G. Canepa and E. Pouliquen, "Inversion of geo-acoustic properties from high frequency multibeam data," in Boundary Influences in High Frequency, Shallow Water Acoustics, Proceedings of a Conference Held at the Department of Physics, edited by N. G. Pace and P. Blondel, 5-9 September 2005, University of Bath, UK (University of Bath, 2005), pp. 233-240.

${ }^{5}$ D. G. Simons and M. Snellen, "A comparison between modeled and measured high frequency bottom backscattering," in Proceedings of the European Conference on Underwater Acoustics, June 29-July 4, 2008, Paris, France, pp. 639-644.

${ }^{6}$ P. A. van Walree, J. Tegowski, C. Laban, and D. G. Simons, "Acoustic seafloor discrimination with echo shape parameters: A comparison with the ground truth," Cont. Shelf Res. 25, 2273-2293 (2005).

${ }^{7}$ A. R. Amiri-Simkooei, M. Snellen, and D. G. Simons, "Principal component analysis of single-beam echo-sounder signal features for seafloor classification," IEEE J. Ocean. Eng. 36(2), 259-272 (2011).

${ }^{8}$ C. Wienberg and A. Bartholomä, "Acoustic seabed classification in a coastal environment (outer Weser Estuary, German Bight)—a new approach to monitor dredging and dredge spoil disposal," Cont. Shelf Res. 25, 1143-1156 (2005).

${ }^{9}$ D. Eleftherakis, A. R. Amiri-Simkooei, M. Snellen, and D. G. Simons, "Improving riverbed sediment classification using backscatter and depth residual features of multi-beam echo-sounder systems," J. Acoust. Soc. Am. 131(5), 3710-3725 (2012).

${ }^{10}$ D. D. Sternlicht and C. P. de Moustier, "Remote sensing of sediment characteristics by optimized echo-envelope matching," J. Acoust. Soc. Am. 114(5), 2727-2743 (2003).

${ }^{11}$ P. A. van Walree, M. A. Ainslie, and D. G. Simons, "Mean grain size mapping with single-beam echosounders," J. Acoust. Soc. Am. 120(5), 2555-2566 (2006).

${ }^{12} \mathrm{X}$. Lurton and E. Pouliquen, "Automated sea-bed classification system for echo-sounders," in Proceedings of the IEEE Oceans 1992 Conference (1992), pp. 317-321.

${ }^{13}$ M. Snellen, K. Siemes, and D. G. Simons, "Model-based sediment classification using single-beam echosounder signals," J. Acoust. Soc. Am. 129(5), 2878-2888 (2011).

${ }^{14}$ D. G. Simons and M. Snellen, "A Bayesian approach to seafloor classification using multi-beam echo-sounder backscatter data," Appl. Acoust. 70, 1258-1268 (2009).

${ }^{15}$ A. R. Amiri-Simkooei, M. Snellen, and D. G. Simons, "Riverbed sediment classification using multi-beam echo-sounder backscatter data," J. Acoust. Soc. Am. 126, 1724-1738 (2009).

${ }^{16} \mathrm{M}$. van Wijngaarden, L. B. Venema, R. J. De Meijer, J. J. G. Zwolsman, B. Van Os, and J. M. J. Gieske, "Radiometric sand-mud characterisation in the Rhine-Meuse estuary, Part A. Fingerprinting," Geomorphology 43, 87-102 (2002).

${ }^{17}$ E. R. van der Graaf, R. L. Koomans, J. Limburg, and K. de Vries, "In situ radiometric mapping as a proxy of sediment contamination: Assessment of the underlying geochemical and -physical principles," Appl. Radiat. Isot. 65, 619-633 (2007).

${ }^{18}$ E. Hammerstad, "Backscattering and Seabed Image Reflectivity," EM Technical Note, Kongsberg, Norway, pp. 1-5 (2000), http://www.km. kongsberg.com/ks/web/nokbg0397.nsf/AllWeb/226C1AFA658B1343C125 6D4E002EC764/\$file/EM_technical_note_web_BackscatteringSeabedImage Reflectivity.pdf?OpenElement (Last viewed 09/06/2011).

${ }^{19}$ APL-UW high-frequency ocean environmental acoustic models handbook," Oct. 1994, technical report APL-UW TR9407AEAS9501, Applied Physics Laboratory, University of Washington, pp. IV1-IV50.

${ }^{20}$ A. R. Amiri-Simkooei, "Formulation of L1 norm minimization in Gauss-Markov models," J. Surv. Eng. 129(1), 37-43 (2003).

${ }^{21}$ K. V. Price, R. M. Storn, and J. A. Lampinen, Differential Evolution. A Practical Approach to Global Optimization (Springer, Berlin, 2005) Chap. 2, pp. 37-131.

${ }^{22}$ M. Snellen and D. G. Simons, "An assessment of the performance of global optimisation methods for geo-acoustic inversion," J. Comput. Acoust. 16(2), pp. 199-223 (2008).

${ }^{23}$ P. H. G. M. Hendriks, J. Limburg, and R. J. de Meijer, "Full-spectrum analysis of natural gamma-ray spectra," J. Environ. Radioact. 53, 365-380 (2001).

${ }^{24}$ R. L. Koomans, "Sand in motion: effects of density and grain size," Ph.D. thesis, RUG, Groningen, 2000, $218 \mathrm{pp}$.

${ }^{25}$ R. Webster and M. Oliver, "Geostatistics for environmental scientists," Statistics in Practice (Wiley, Chichester, 2001). 